\title{
Learning "Outside the Toy Box"
}

\author{
Jason M. Keith \\ Department of Chemical Engineering, Michigan Technological University, \\ Houghton, MI 49931
}

\begin{abstract}
This paper describes the use of educational tools to teach chemical engineering undergraduate students the fundamentals of electric circuits and control systems for a bench scale chemical mixing plant prototype. It was found that having access to kits aimed at elementary and middle school students aided student learning of these challenging multidisciplinary concepts. A strategy for using these tools for student projects, both simple and advanced, is outlined.

Introduction

Team-based, hands-on, multidisciplinary design projects have seen an increased place in the chemical engineering curriculum, especially with the advent of the new criteria set forth by the Accreditation Board of Engineering and Technology. However, even with these efforts, students are often challenged to learn advanced engineering topics outside of their major discipline on their own or with help from their instructor. This often results in student frustration and a lack of learning.

At the same time, engineers inherently are fascinated with children's toys that focus on or utilize simple engineering fundamentals. For example, there are many simple wooden puzzles that are for kids all ages. They keep children occupied and can challenge the mind of even the most intelligent people. These toys possess the capability of providing high level learning skills.

In order to increase student learning in design projects, these procedures have been implemented in a new elective chemical engineering course at Michigan Technological University, CM4900: Interdisciplinary Design. The project that the students worked on focused on the development and construction of a prototype bench scale reactor to mix three fluids together in a desired proportion. For their electrical networks, students used one of two electronic kits to develop a foundation of knowledge in electronic circuits:
\end{abstract}

- the BASIC Stamp II Microprocessor, manufactured by Parallax, Inc., which consists of a breadboard and microprocessor, textually programmed on a PC

- the recently developed Lego Mindstorms Kit, which is a giant programmable Lego brick that easily reads sensor input and provides output to motors. The 8-bit microprocessor (known as the RCX) can be programmed with a LabVIEW like interface or with a text based program in C (named NQC for Not-Quite-C). 
Students also utilized "black boxes" obtained from companies that their parents work for in order to complete their designs. After providing a description of the project and ways to use the microprocessor to teach advanced concepts, this paper will describe these learning experiences.

\section{Brief Project Description}

During the Fall 2000 and Fall 2001 semesters, students in CM4900 worked to achieve the following goals:

1. Produce a prototype of an automated chemical delivery production facility known as a "Widespread Industrial Novel Multifluid Turnout Unit" (a.k.a. WIN MTU Project) which is to be designed to mix together three fluids: distilled water, distilled water with $1 \%$ by mass salt, and distilled water with $1 \%$ by mass red food coloring.

2. Construct a numerical model to predict the performance of the prototype.

For more information regarding the goals, learning objectives, and description of the student project in Interdisciplinary Design, the reader is referred to an earlier ASEE conference proceedings. ${ }^{1}$

\section{A Strategy for Teaching Chemical Engineers Electronics and Process Control}

\section{Fundamentals}

The Lego RCX is well suited to provide an introduction to basic circuitry and electronics to chemical engineering students. These basics are best understood with an illustrative example. The internals of the RCX have been reverse-engineered and are well documented in the literature. $^{2-9}$ Underneath the exterior, the RCX contains a 5 volt power supply connected with a 10 kilo-ohm internal resistance. To complete the circuit, one must connect something to a terminal input (labeled as 1, 2, or 3) on the Lego RCX, as seen in figure 1.

The display area can be selected for any input or output. The display shows a 10-bit number (a number between 0 and $2^{10}-1=1023$ ) called the "raw value" which corresponds to the voltage across the input terminals. From this calculation, one can infer the resistance of the object connected to input 2 .

Students can identify the magnitude of the voltage source by connecting a voltmeter to the input terminals, and the magnitude of the internal resistance by connecting known resistances to the input terminals and measuring the voltage drop across them. The voltage divider law states that the voltage drop across the input terminals is equal to

$$
V_{a b}=V_{s} \frac{R_{s}}{R_{s}+R_{a b}}
$$


For an open circuit, $\mathrm{R}_{\mathrm{s}} \sim \infty$ such that $\mathrm{V}_{\mathrm{ab}}=\mathrm{V}_{\mathrm{s}}=5 \mathrm{~V}$. The corresponding raw value is 1023. For a short circuit, $\mathrm{R}_{\mathrm{ab}} \sim 0$ such that $\mathrm{V}_{\mathrm{ab}}=0$. The corresponding raw value is 0 . Thus, the relationship between the raw value and the voltage across the input terminals is:

$R A W=1023 \frac{V_{a b}}{V_{s}}$

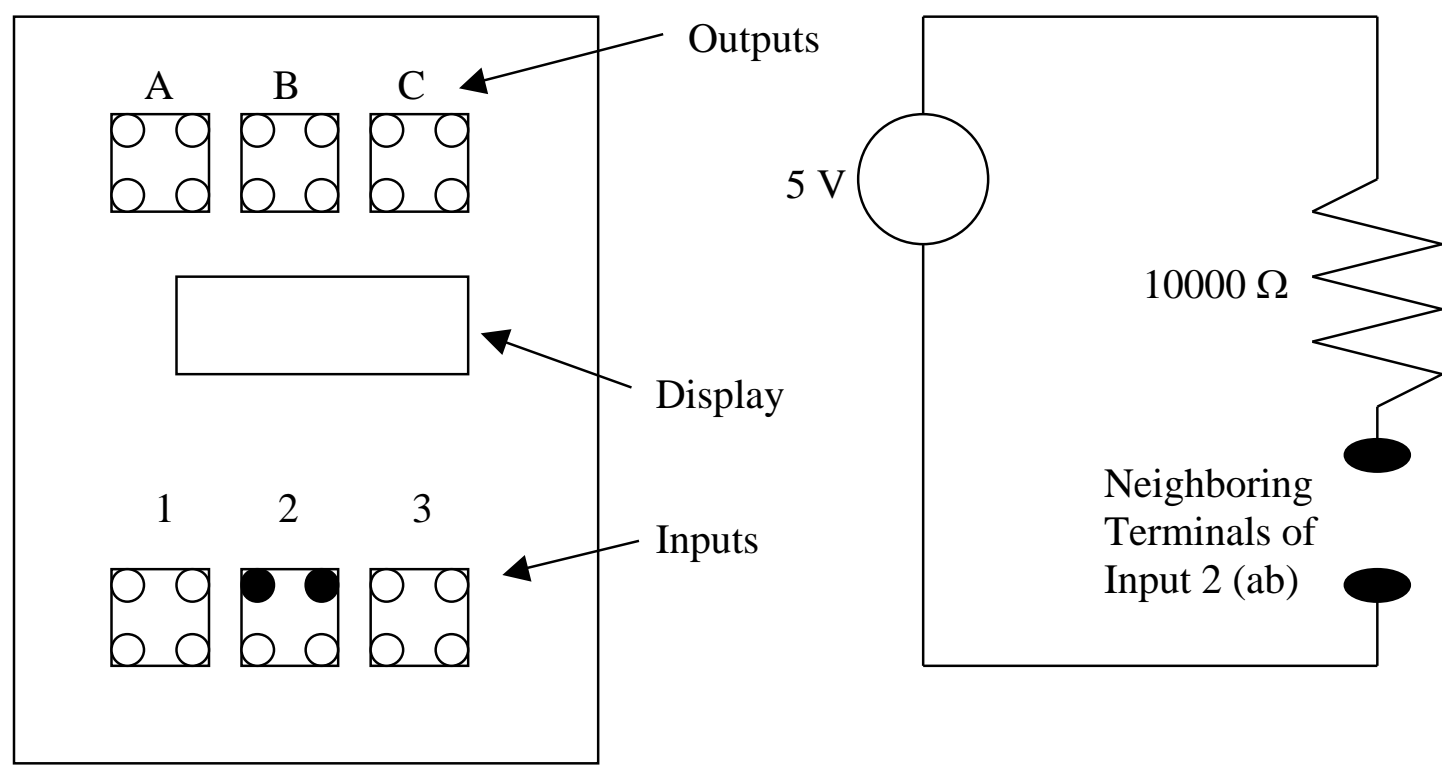

Figure 1. Schematic of RCX

One can infer the value of $\mathrm{R}_{\mathrm{s}}$ by adding any resistance across the terminals. For example, $\mathrm{R}_{\mathrm{ab}}=$ $10,000 \Omega$, the raw value is 512 . Thus, one can compute $R_{s}=10,000 \Omega$. Students can also apply fundamental laws of circuitry including Kirchoff's Voltage Law and Kirchoff's Current Law by building complex parallel and series circuits on a breadboard and interfacing them with the RCX.

\section{Advanced Applications: Sensors / Control}

The RCX also makes for easy understanding of control systems. For the design project, students were required to measure the amount of red dye in a distilled water solution. This was accomplished through the use of a photoresistor, as seen in figure 2 below. The resistance of the photoresistor changes with the amount of light entering it.

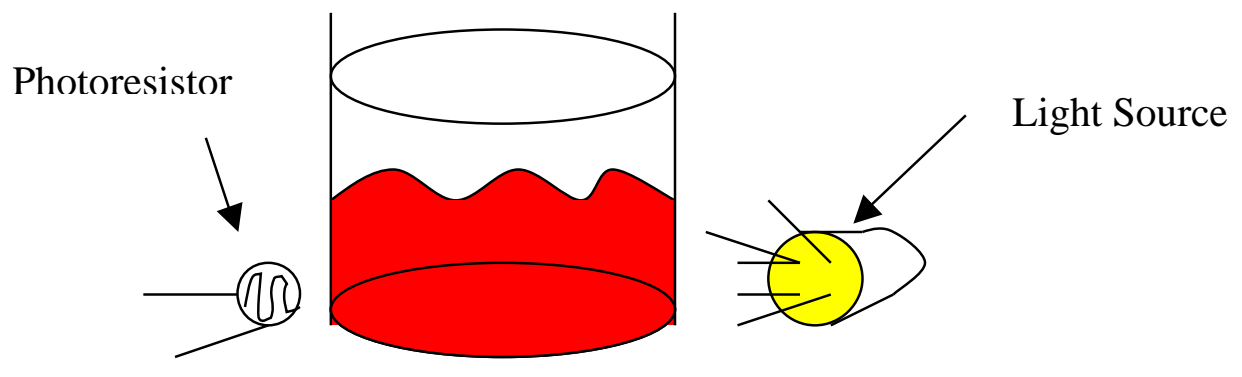

Figure 2: Photoresistor

Proceedings of the 2002 American Society for Engineering Education Annual Conference \& Exposition

Copyright (C) 2002, American Society for Engineering Education 
Students found that the concentration of red dye was not directly proportional to the resistance of the photoresistor. They had to calibrate their instrumentation (and thus their RCX program) to open and close the valves to reach a desired RCX raw value, corresponding to the desired amount of red dye.

The students were also required to measure the amount of salt in a solution of distilled water. This was accomplished through the use of a conductivity meter. A simple meter is shown in figure 3, where two bare copper wires are inserted into the solution. The problem of polarization is countered by adding a 555 timer to rapidly pulse the charge.

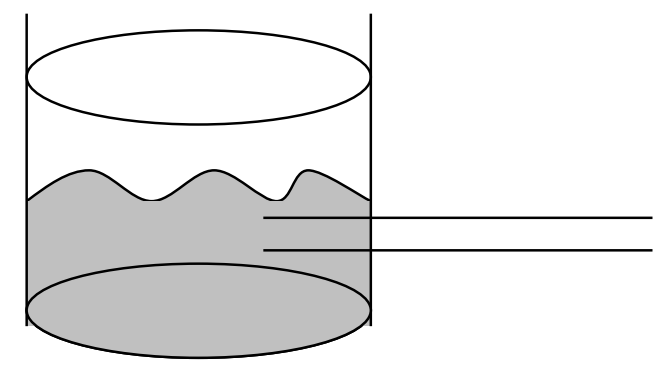

\section{Figure 3: Conductivity Meter}

To properly use their controller, the students needed to develop calibration curves for their salt sensor. In addition to performing manual calibrations, students looked at the literature regarding light intensity detected by a photoresistor and conductivity of standard salt solutions. This gave them an empirical understanding of the sensor itself and made for the development of a simple control system. This was suitable since the actuators used during the most recent term were solenoid (on/off) valves. A schematic of the mixing system is shown in figure 4.

\section{Student Experiences and Learning}

One student group worked on the WIN MTU Project during Fall 2000 and was provided with a BASIC Stamp II Microprocessor, a Stamp II Servo Controller, and three servo motors (all items are manufactured by Parallax, Inc.). The goal was to interface the controller (microprocessor) with simple sensors (such as using the photoresistor for the red dye detector and two wires for a conductivity detector) and an actuator (servo motor) for each of the three fluids.

The following learning outcomes were observed:

- The student group learned the valuable lesson that ordering experimental equipment takes time, as the arrival of a salt conductivity sensor was delayed.

- The students felt that the project was not a total success. This is because the servo motors did not have enough torque to open the plastic stopcock valves the group had chosen. The group could only give a semi-quantitative demonstration, where a servo motor was rotated to one of two positions (but did not open or close the stopcock valve) depending on the amount of red dye in the container. 
- Both of these experiences meant that the students learned to anticipate problems when designing experiments, and that nothing goes right the first time. This knowledge is especially useful for students preparing to enter graduate school or a career in industry.

- Since the students waited until the last minute to construct their prototype, they consequently felt unmotivated to construct a numerical model.

\section{Salt Water Distilled Water Red Water}

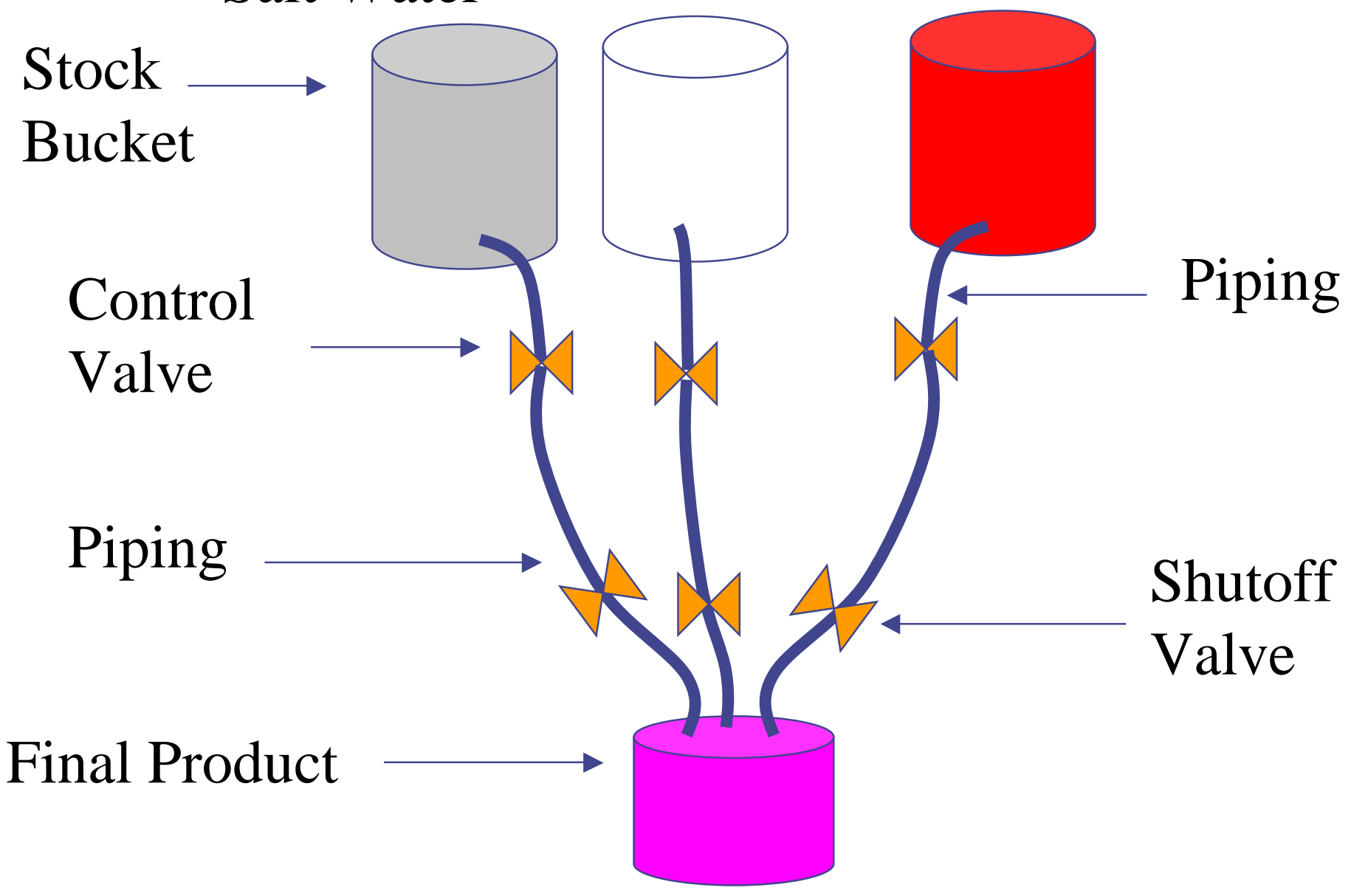

Figure 4: Mixing System

During the fall 2001 semester, two independent groups worked on the WIN MTU Project. The groups were each provided a Lego Mindstorms kit with the RCX to use as their controller. There are several web sites ${ }^{2-6}$ and books ${ }^{7-9}$ dedicated to using the RCX to do just about anything. This makes it an ideal choice for an instructor since a lot of the work learning how the RCX works and what it can do has been done already and well documented.

To encourage student thinking "outside the box," students began the project phase with a "brainstorming session." The instructor brought in several wooden puzzles that were purchased 
at a local fair, some old Rubik's cubes, and some TAPPS (Thinking Aloud Pairs Problem Solving) problems. ${ }^{10}$ Two additional class sessions were devoted to allowing the students to work through the computer tutorial for the Lego RCX. The students especially enjoyed playing with Lego blocks, telling their friends who were taking "boring electives."

The Lego Mindstorms kit includes two motors. Since it was anticipated by the instructor that the groups would use the motors to open and close valves, additional motors were purchased from the Lego website.

The following learning outcomes were observed:

- The groups took their own initiative to ask for help from the staff of the chemical engineering machine shop for help with their design. They were given a box of solenoid valves to use as their actuators. This worked well since the valves they used were "normally off" and opened only when energized. The students recognized two advantages: ease in meeting safety regulations AND implementing on/off control.

- $\quad$ Requiring intermediate deliverables helped the groups create a successful prototype. Student groups felt proud of their abilities to create a functional prototype.

- Having two groups led to competition between the groups. Students wanted to be in the best group.

- One group of students recognized that using on/off valves made developing a theoretical model of the fluid mixing process quite simple, and accurately modeled the process.

- The groups were able to track expenses with a budget.

In addition to meeting these learning outcomes, students gained the following knowledge from using the Basic Stamp and Lego Mindstorms microprocessor:

- Independence - after completing the tutorial, student groups were able to independently develop the entire experimental procedure, phases of which are outlined in the bulleted points below. Working independently through this process instilled confidence in the students' abilities to perform experiments and analysis.

- Fundamentals of electric circuits - students verified simple formulas for predicting the equivalent resistance of a complex circuit; also students learned how to use more advanced electronic devices such as potentiometers, capacitors, diodes, and relays.

- Computer programming - students learned computer programming basics using a text based language or a graphical user interface.

- Data acquisition - students were able to use microprocessors to collect data from simple experiments performed in the lab.

- Sensor calibration - after constructing a set of experimental data, students were able to predict sensor output for a variety of conditions.

- Controller design - students were able to synthesize and use the calibration information to design a controller to produce a desired quantity and quality of "red salt water."

Most importantly, by playing with Legos, students learned these concepts while having fun. 


\section{Conclusions}

The use of educational toolkits to teach chemical engineering students advanced concepts such as electrical circuits and control systems has been described. Students learned and had fun while doing it. Shown below are unsolicited quotes from students who have enrolled in CM4900:

- "During the course of the project we broadened our electrical engineering, computer science, and mechanical engineering skills. We believe we have learned interdisciplinary concepts and that we can apply this knowledge to future projects."

- "I have told the underclassmen about this class. This has been the best elective class I have taken while at Michigan Tech. I have learned a lot."

- "Presentation given to management. Demonstration performed well. It worked. Now I am almost disappointed its over. It was a real fun class with a great instructor who is funny."

Consider teaching a hands-on class or implementing hands-on activities into one of your classes. The students will thank you for it.

Bibliography

1. Keith, J. M., Dugar, C., Meyer, J., and Norman, N., "A Hands-On Multidisciplinary Design Course for Chemical Engineering Students," ASEE Conference Proceedings (2001).

2. Not Quite C (NQC) programming language, http://www.enteract.com/ dbaum/lego/nqc/

3. RCX code command center, http://www.cs.ruu.nl/people/markov/lego/rcxcc/index.html

4. RCX internals, http://graphics.stanford.edu/ kekoa/rcX

5. Mindstorms RCX sensors, http://www.plazaearth.com/usr/gasperi/lego.htm

6. Lego User's Group network, http://www.lugnet.com/

7. D. Baum, M. Gasperi, R. Hempel, and L. Villa (Eds.) Extreme Mindstorms: an Advanced Guide to LEGO Mindstorms, Apress, Berkeley, CA (2000).

8. M. Ferrari, G. Ferrari, R. Hempel, Building Robots with LEGO Mindstorms: The Ultimate Tool for Mindstorms Maniacs, Syngress, Rockland, MA (2001).

9. D. Baum, R. Zurcher, Dave Baum's Definitive Guide to LEGO Mindstorms, Apress, Berkeley, CA (2000).

10. Lochhead, J. and Whimbey, A., "Teaching Analytical Reasoning Through Thinking Aloud Pairs Problem Solving," in J. E. Stice (Ed.), New Directions for Teaching and Learning, No. 30, Developing Critical Thinking and Problem Solving Abilities, San Francisco: Jossey-Bass (1987).

\section{JASON M. KEITH}

Jason Keith is an Assistant Professor of Chemical Engineering at Michigan Technological University, and is the instructor for the course titled CM4900 Interdisciplinary Design 1. He received his PhD from the University of Notre Dame in August 2000. While at Notre Dame Jason was active in the development of a new freshman engineering sequence EG111/EG112 Introduction to Engineering Systems, serving as a graduate instructor. 